\title{
molecules
}

ISSN 1420-3049

http://www.mdpi.org/

\author{
Full Paper
}

\section{Evaluation of the Antioxidant Properties of Litchi Fruit Phenolics in Relation to Pericarp Browning Prevention}

\author{
Xuewu Duan ${ }^{1}$, Genfu Wu ${ }^{2}$ and Yueming Jiang ${ }^{1, *}$ \\ ${ }^{1}$ South China Botanical Garden, The Chinese Academy of Sciences, Guangzhou Leyiju 510650; P. R. \\ China; E-mail: xwduan@scib.ac.cn \\ ${ }^{2}$ College of Life Sciences, Zhejiang University, Hangzhou 310012; P. R. China; \\ E-mail: wugenfu@zju.edu.cn
}

* Author to whom correspondence should be addressed: Email: ymjiang@scbg.ac.cn;

Tel.: (+86) 20 37252525; Fax: (+86) 2037252831

Received: 14 March 2007; in revised form: 25 March 2007 / Accepted: 30 March 2007 / Published: 11 April 2007

\begin{abstract}
Phenolics were extracted from litchi fruit pericarp (LFP) tissues, purified and their antioxidant properties analyzed. LFP phenolics strongly inhibited linoleic acid oxidation and exhibited a dose-dependent free-radical scavenging activity against $\alpha, \alpha-$ diphenyl- $\beta$-picrylhydrazyl (DPPH·) and hydroxyl radicals and superoxide anions. The degradation of deoxyribose by hydroxyl radicals was inhibited by phenolics acting mainly as iron ion chelators, rather than by directly scavenging the radicals. Phenolics from litchi fruit pericarp were found to display similar reducing power activity as ascorbic acid. The effect of phenolic compound treatment on pericarp browning and electrolyte leakage of litchi fruit was also evaluated and it was observed that application of exogenous litchi phenolics to harvested litchi fruit significantly prevented pericarp browning and delayed increases in electrolyte leakage. These results suggest that litchi pericarp tissue phenolics could be beneficial in scavenging free radicals, maintaining membrane integrity and, thereby inhibiting pericarp browning of litchi fruit.
\end{abstract}

Keywords: Litchi chinenesis Sonn; phenolics; antioxidant activity; reducing power; free radicals; lipid peroxidation. 


\section{Introduction}

Oxidation is essential to many living organisms for the production of energy necessary for biological processes. However, reactive oxygen species (ROS) are produced in vivo during some oxidative reactions [1] and these species are not only strongly associated with lipid peroxidation, leading to food deterioration, but also involved in development of a variety of diseases including cellular aging, mutagenesis, carcinogenesis, coronary heart disease, diabetes and neurodegeneration [2,3]. Although almost all organisms possess antioxidant defense and repair systems to protect them from oxidative damage, in some cases these systems are insufficient to entirely prevent such damage [4]. In the case of foods, over time the decreased protective ability of the antioxidative defenses can be overcome by the ROS, leading, for example, to cellular damage during postharvest storage of fruit [5]. Currently, there is a trend towards replacement of the widely used synthetic antioxidants, such as butylhydroxyanisole (BHA) and butylated hydroxytoluene (BHT), with antioxidants from natural sources to extend the shelf life of foods [6].

Fruits and vegetables are known to contain a variety of different antioxidant compounds such as ascorbic acid, tocopherol, glutathione and carotenoids, which may all contribute to protection against oxidative damage [1]. It has been recently shown that phenolics from edible fruits are effective in vitro antioxidants $[7,8]$. The antioxidative properties of phenolics arise from their high reactivity as hydrogen or electron donors and from the ability of polyphenol-derived radicals to stabilize and delocalize the unpaired electron or from their ability to chelate transition metal ions (i.e. cause termination of the Fenton reaction) [9]. Some reducing compounds or antioxidants, such as ascorbic acid and glutathione, are very efficient in controlling enzymatic browning $[10,11]$. Thus, endogenous phenolics may also play a role in inhibiting fruit browning processes.

Litchi (Litchi chinensis Sonn.) is a tropical to subtropical fruit native to China, Vietnam, Indonesia and the Philippines, but now also grown elsewhere in the world. The fruit has a bright red pericarp surrounding a white aril [5]. Litchi pericarp contains large amounts of phenolics [12]. In our preliminary study, the phenolics content of harvested litchi fruit pericarp tissues was $13.9 \mathrm{mg} / \mathrm{g}$ on a fresh weight basis (Duan and Jiang, unpublished data). The major phenolics in litchi fruit pericarp tissues were identified as epicatechin, procyanidin B4 and procyanidin B2 (Figure 1). Furthermore, although a number of phenolics have been identified in different litchi cultivars [12,13], little information is available about the antioxidant activity of these phenolics from litchi fruit peel. The objective of the current study was to evaluate the antioxidant property of phenolics from litchi fruit pericarp tissues and then investigate the effects of exogenous phenolic treatments on the pericarp browning of the fruit.

\section{Results and Discussion}

\section{Extraction and purification of phenolics from litchi fruit pericarp}

Litchi pericarp contains a large amount of phenolics [5]. In this study, the measured content of phenolics in litchi pericarp tissues after purification was about $11.8 \mathrm{mg} / \mathrm{g}$ fresh weight. In a previous study, we extracted and purified phenolics from the pericarp tissue of Huaizhi cv. litchi and found that the major flavonoids present were epicatechin, procyanidin B2 and procyanidin B4 (Figure 1) [14]. 
Zhang et al. [12] have reported that the phenolic constituents of litchi fruit pericarp are mainly epicatechin, epicatechin 3-gallate and procyanidin B2, while Sarni-Manchado et al. [13] have mentioned condensed tannins, epicatechin and procyanidin A2 as the major phenolic compounds found in litchi fruit pericarp. We attribute the observed differences to the use of different cultivars in these studies.

Figure 1. Three major flavonoids from pericarp tissues of Huaizhi cv. litchi [14].<smiles>Oc1cc(O)c2c(c1)O[C@H](c1ccc(O)c(O)c1)[C@H](O)C2</smiles>

Epicatechin<smiles>Oc1cc(O)c2c(c1)O[C@H](c1ccc(O)c(O)c1)[C@H](O)C2c1c(O)cc(O)c2c1O[C@H](c1ccc(O)c(O)c1)[C@H](O)C2</smiles>

Procyanidin B4<smiles>Oc1cc(O)c2c(c1)O[C@H](c1ccc(O)c(O)c1)[C@H](O)C2c1c(O)cc(O)c2c1O[C@H](c1ccc(O)c(O)c1)[C@H](O)C2</smiles>

Procyanidin B2

\section{Antioxidant activity in a linoleic acid system}

As shown in Figure 2, phenolics from litchi pericarp tissues can significantly inhibit peroxidation of linoleic acid and reduce the formation of hydroperoxides, implying that these phenolics are powerful natural antioxidants. The measured antioxidant activity of the litchi phenolics was nevertheless slightly lower than that of BHT, a widely used commercial antioxidant.

\section{Reducing power}

Reducing power is widely used to evaluate the antioxidant activity of polyphenols $[8,15,16]$. As shown in Figure 3, phenolics from litchi pericarp tissues exhibited higher reducing power than BHT and similar reducing power to ascorbic acid, suggesting that the litchi phenolics possess strong electron donating capacity. Furthermore, a linear relationship existed between the concentration and reducing power of ascorbic acid, BHT and litchi phenolics, with correlation coefficients of $0.9997(\mathrm{y}=0.0036 \mathrm{x}+$ 0.0412), $0.9958(y=0.0014 x+0.025)$ and $0.9990(y=0.0038 x+0.1039)$ for ascorbic acid, BHT and the litchi phenolics, respectively. 
Figure 2. Antioxidant activity of phenolics from litchi pericarp tissues, measured by the ferric thiocyanate method.

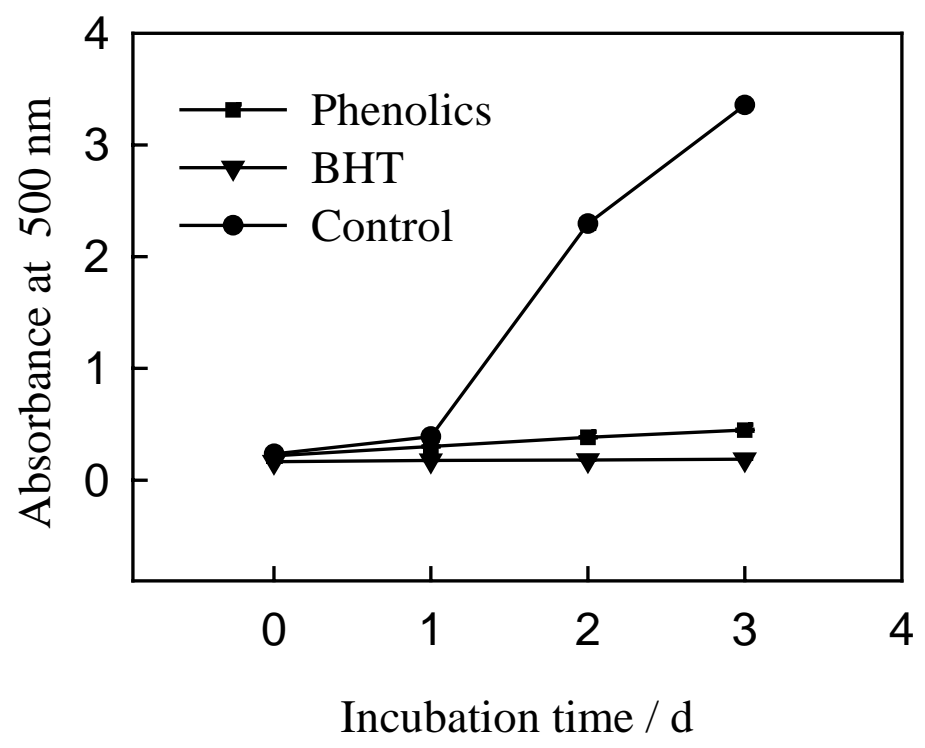

Luximon-Ramma et al. [16] have reported the existence of a similar apparent linear relationship between antioxidant capacity (assessed as ferric ion reducing power) and total phenol content in Cassia fistula extracts. Other similar findings have been obtained in assessments of the antioxidant activities of crude extracts of Ribes, Rubus and Vaccinium [17], fruit juices [18] and red wine [19].

Figure 3. Reducing power of phenolics from litchi pericarp tissues.

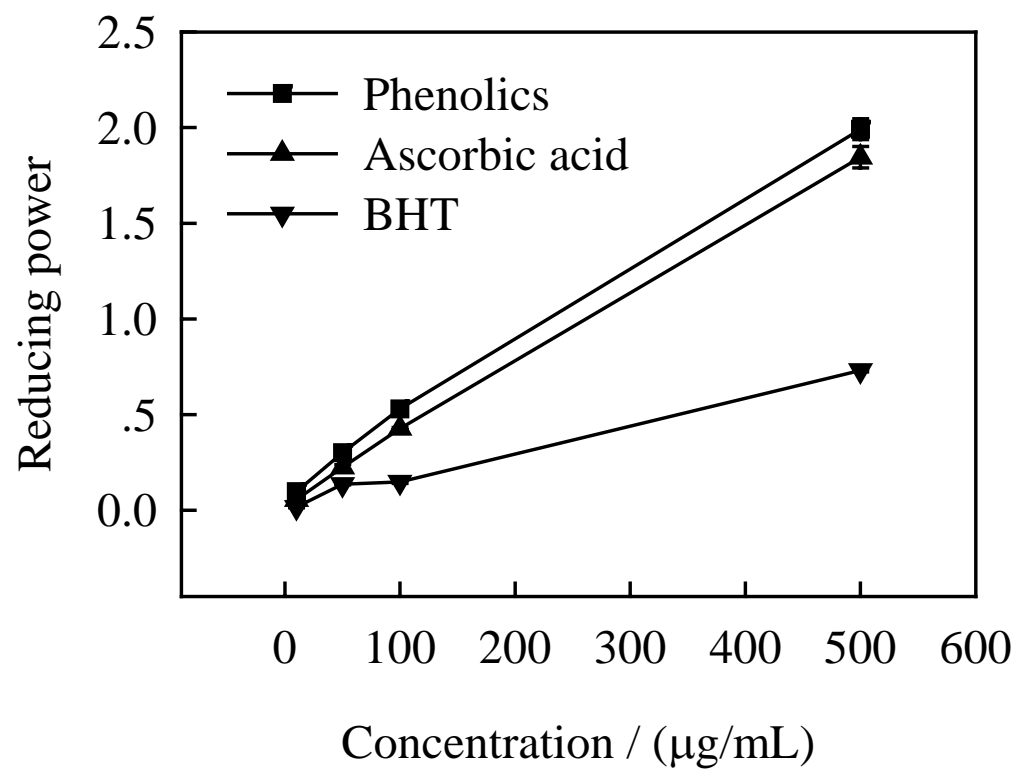

$D P P H \cdot$ radical scavenging activity

Free radical scavenging is one of the known mechanisms whereby antioxidants inhibit lipid peroxidation [1,9]. The DPPH radical scavenging activity assay has been used extensively for screening antioxidants from fruit and vegetable juices or extracts [20]. Figure 4 compares the DPPH radical 
scavenging activity of litchi phenolics, ascorbic acid and BHT. The litchi phenolics exhibited a dose-dependent DPPH' radical scavenging activity. Furthermore, these litchi phenolics had the highest such scavenging activity, followed by ascorbic acid and BHT, respectively.

Figure 4. Scavenging effect of phenolics from litchi pericarp tissues on DPPH radicals.

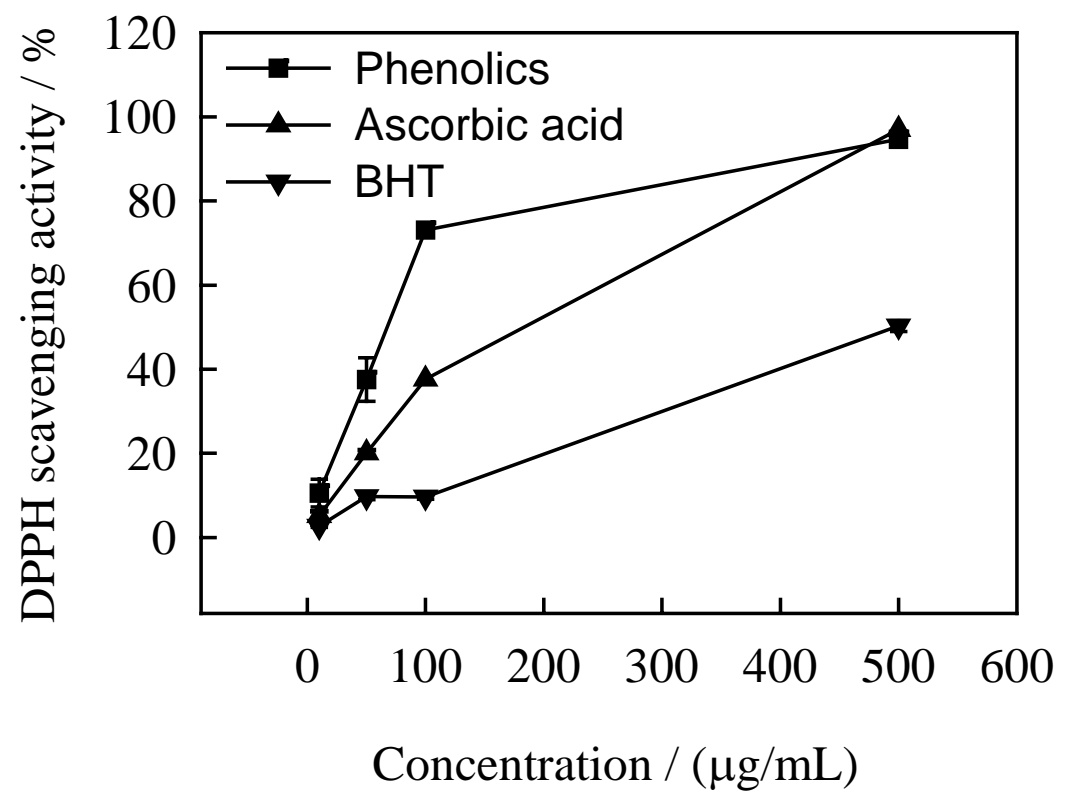

At $100 \mu \mathrm{g} / \mathrm{mL}$, the DPPH radical scavenging activities of litchi phenolics, ascorbic acid and BHT were $73.09 \%, 37.64 \%$ and $9.65 \%$, respectively. Sun et al. [21] investigated antioxidant properties of 11 different fruits (including cranberry, apple, red grape, strawberry, pineapple, banana, peach, lemon, orange, pear, and grapefruit) using a total oxyradical scavenging capacity (TOSC) assay, and also found that there was a direct relationship between total phenolic content and total antioxidant activity in extracts of these fruits.

Figure 5. Superoxide radical scavenging activity of phenolics from litchi pericarp tissues.

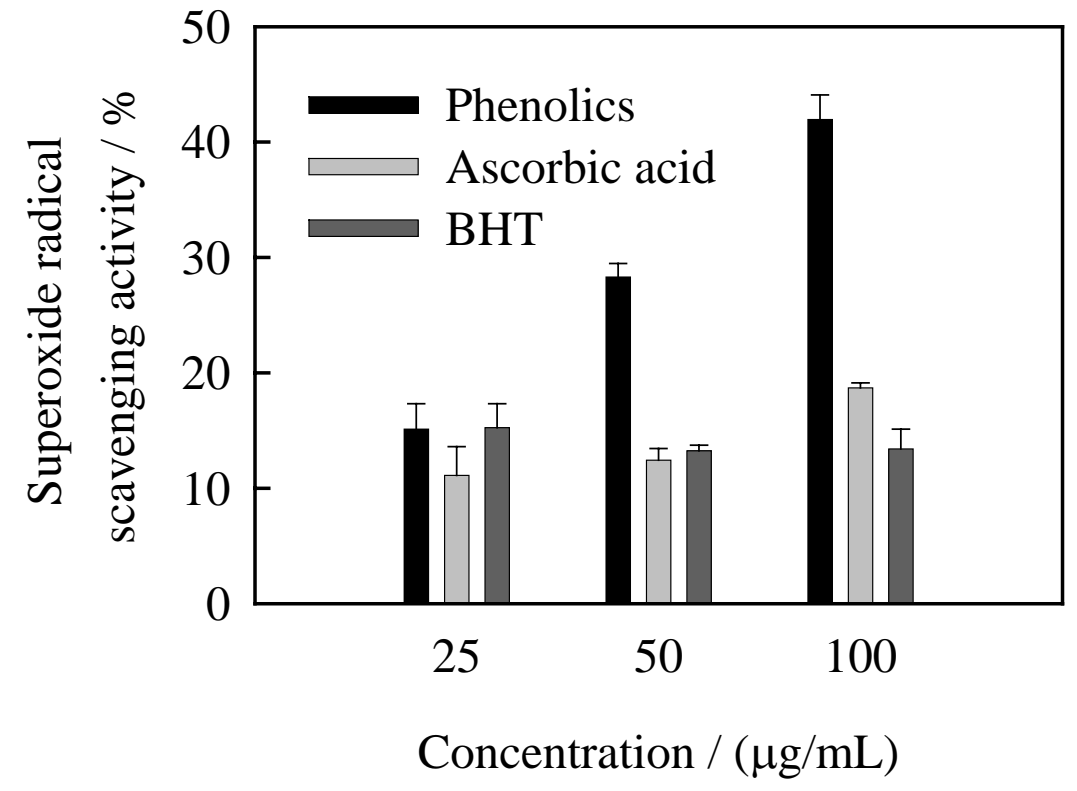




\section{Superoxide anion scavenging activity}

Superoxide anion radicals are produced by a number of cellular reactions, including various enzyme systems, such as lipoxygenases, peroxidase, NADPH oxidase and xanthine oxidase. Superoxide anion plays an important role in plant tissues and is involved in the formation of other cell-damaging free radicals [1]. The relative scavenging effects of litchi phenolics towards superoxide radicals are compared with those of ascorbic acid and BHT in Figure 5. At $50 \mu \mathrm{g} / \mathrm{mL}$ the litchi phenolics exhibited the strongest superoxide anion scavenging activity, compared to ascorbic acid and BHT, with values of $28.30 \%, 12.42 \%$ and $13.25 \%$, respectively.

\section{Inhibitory effects of deoxyribose degradation}

Hydroxyl radicals can be formed by the Fenton reaction in the presence of reduced transition metals such as $\mathrm{Fe}^{2+}$ and $\mathrm{H}_{2} \mathrm{O}_{2}$, which is known to be the most reactive of all the reduced forms of dioxygen, capable of damaging almost every molecule found in living cells [22]. These radicals have the capacity to join with the nucleotides in DNA and cause strand breakage, which contributes to carcinogenesis, mutagenesis and cytotoxicity [3].

In addition, this species is considered to be one of the quick initiators of the lipid peroxidation process, due to abstraction of hydrogen atoms from unsaturated fatty acids [22]. To determine whether litchi phenolics could reduce hydroxyl radical generation either by chelating metal ions or by directly scavenging hydroxyl radicals, the effects of the litchi phenolics on hydroxyl radicals generated by $\mathrm{Fe}^{3+}$ ions were analyzed by determining the degree of deoxyribose degradation. Figure 6 shows the concentration-dependent inhibition of hydroxyl radicals by litchi phenolics in both the site-specific and non-site-specific assays.

Figure 6. Inhibitory effect of phenolics from litchi pericarp tissues on deoxyribose degradation in non-site-specific and site-specific assay.

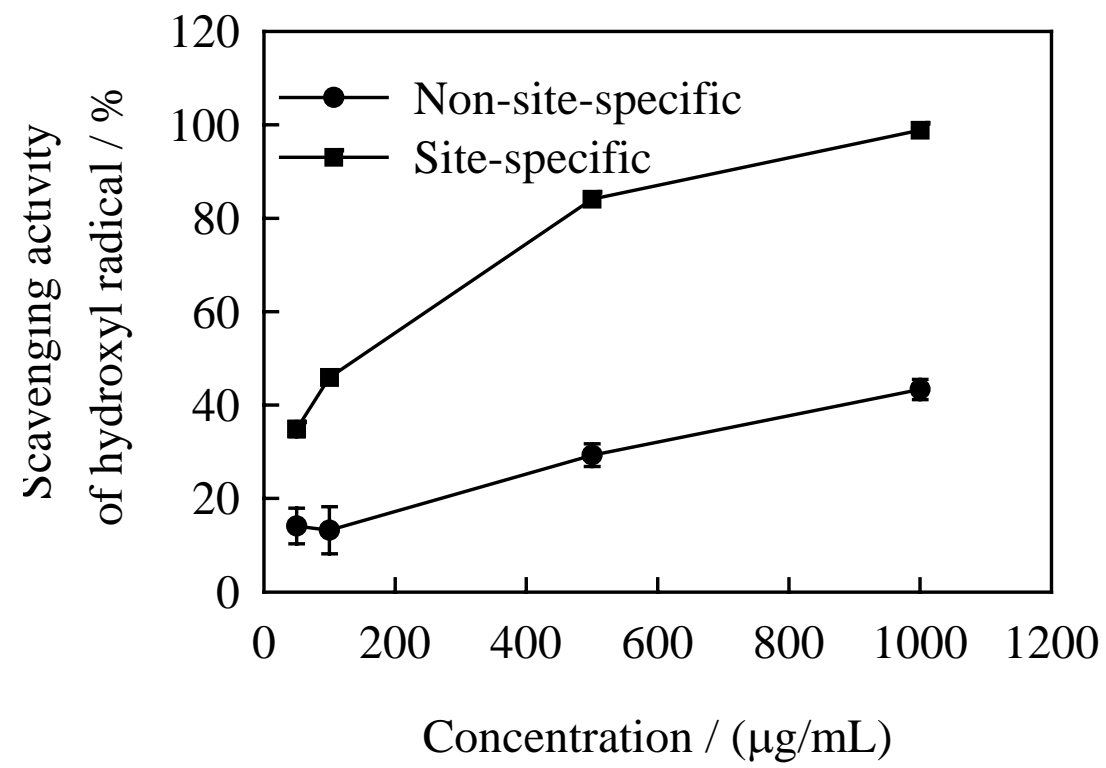


Using the same concentrations, relatively greater antioxidant activity was observed in the site-specific assay than in the non-site-specific one, implying that the litchi phenolics inhibited deoxyribose degradation mainly by chelating metal ions rather than by directly scavenging hydroxyl radicals. Similar results were reported for the crude extracts of Opuntia ficus-indica var. Saboten [23] and Hypericum perforatum L. [24].

Effect of litchi phenolics treatment on pericarp browning and relative electrolyte leakage rate of litchi fruit

As shown in Figure 7A, the pericarp browning index of litchi fruit increased rapidly with storage time. Application of litchi phenolics reduced the pericarp browning index. After 6 days of storage, the browning index for control fruit was 4.95 , while fruit treated with litchi phenolics had a browning index of 4.35 .

Figure 7. Effect of exogenous phenolics on pericarp tissues browning (A) and relative leakage rate (B) of litchi fruit during storage at $28^{\circ} \mathrm{C}$.
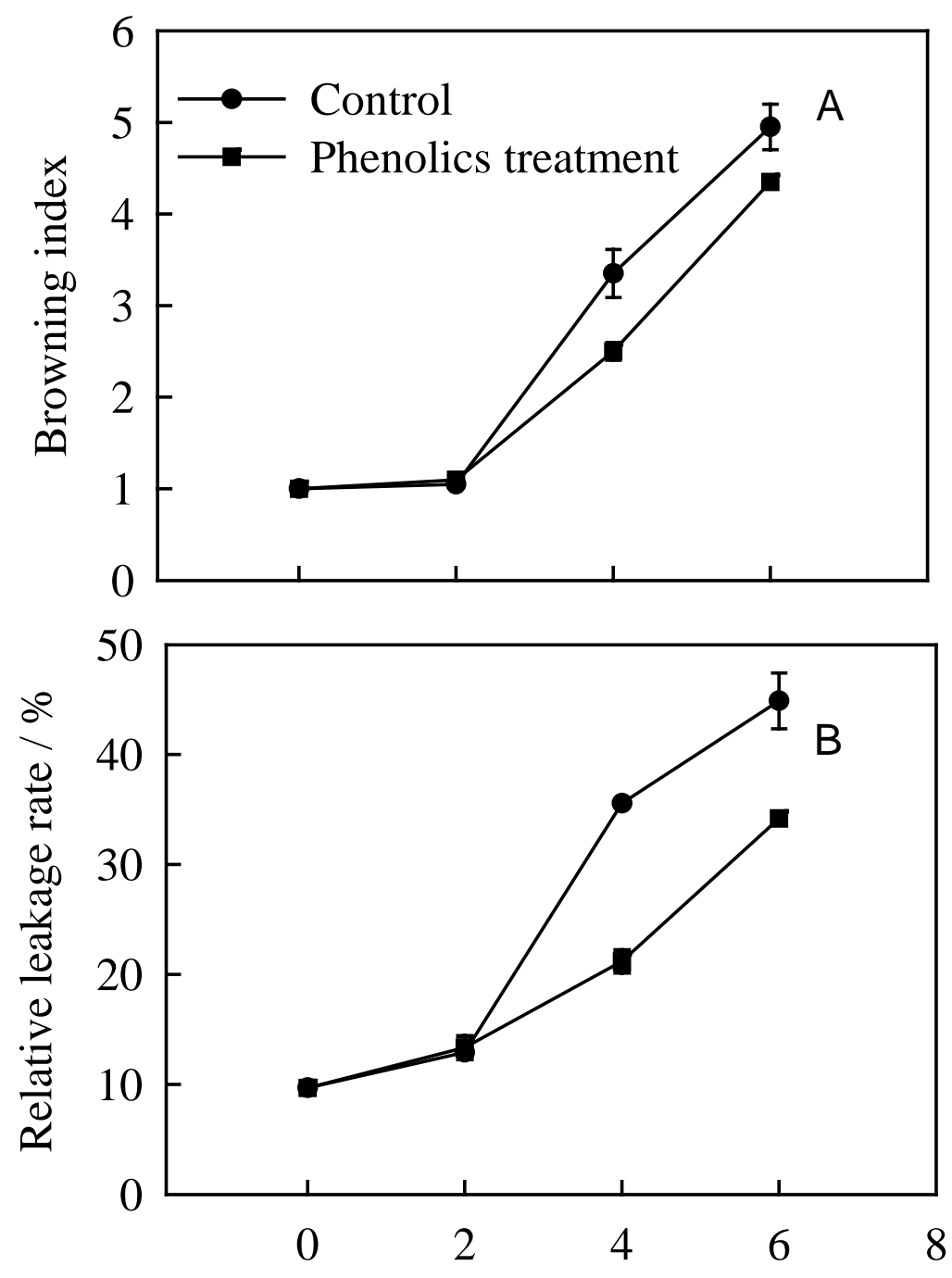

Storage time / d 
Browning is associated with loss of membrane integrity which occurs during tissue deterioration and senescence [25,26]. Electrolyte leakage, as an indicator of membrane integrity, gradually increased during storage. However, fruit treated with litchi phenolics had a significantly lower relative leakage rate than control fruit (Figure 7B), indicating that membrane integrity was partially maintained. There is a great deal of evidence showing that lipid peroxidation, which results from a decreased ability to scavenge reactive oxygen species, leads to loss of membrane integrity and pericarp browning of harvested litchi fruit $[5,10]$. Thus, treatment with litchi phenolics increased free radical scavenging activity, which was possibly beneficial in inhibiting lipid peroxidation and maintaining membrane integrity of pericarp tissues of harvested litchi fruit, which in turn may be responsible for reduced browning.

\section{Conclusions}

Litchi phenolics exhibited excellent antioxidant activity. They significantly inhibited the peroxidation of linoleic acid, and acted as a strong electron-donating agent in the $\mathrm{Fe}^{3+}$ to $\mathrm{Fe}^{2+}$ assay and a hydrogen-donating agent in the DPPH assay. Furthermore, the phenolics from litchi pericarp tissues were effective in scavenging superoxide anion radicals and inhibiting deoxyribose degradation induced by hydroxyl radicals, mainly via chelation of iron ion. In addition, exogenous treatment with litchi phenolics significantly delayed increase in electrolyte leakage and prevented pericarp browning of the fruit, which may be attributed to a strong antioxidant activity.

\section{Experimental}

\section{Plant materials}

Litchi (Litchi chinensis Sonn.) Huaizhi cv. fruits at the commercial mature stage were obtained from an orchard in Guangzhou, China. Fruits were selected for uniformity of shape and color, while blemished or diseased fruit were discarded. The fruits were dipped in a $0.1 \%$ Sportak $^{\circledR}$ (prochloraz, Bayer) fungicide solution for $3 \mathrm{~min}$. and air-dried for $2 \mathrm{~h}$. at $28{ }^{\circ} \mathrm{C}$, prior to the treatment with the solutions containing the litchi phenolic compounds.

\section{Extraction and purification of phenolics}

Phenolic compounds were extracted and purified according to Zhang et al. [12]. Fresh litchi pericarp (50 g) was cut into small pieces, then ground under liquid nitrogen with a pestle and mortar, and finally extracted for $30 \mathrm{~min}$. by stirring at $4{ }^{\circ} \mathrm{C}$ with cold aqueous ethanol (65\%, $500 \mathrm{~mL}$ ) containing $0.5 \%$ sodium metabisulphite. The homogenate was filtered through four layers of cheesecloth, and the residue was then extracted with two additional portions ( $250 \mathrm{~mL}$ each) of the same extraction solution as described above. The combined filtrate was centrifuged at 7,000 $\times \mathrm{g}$ for $15 \mathrm{~min}$. at $4{ }^{\circ} \mathrm{C}$ and residue was discarded. Ethanol was removed from the supernatant under vacuum on a rotary evaporator at $35^{\circ} \mathrm{C}$, and the pigments were eliminated by two successive extractions with petroleum ether. After addition of $20 \%$ ammonium sulphate and $2 \%$ metaphosphoric acid to the aqueous phase, phenolic compounds were 
extracted three times with ethyl acetate. The extracts were combined, evaporated and then dried under vacuum at $35{ }^{\circ} \mathrm{C}$. The residue was re-dissolved in methanol $(20 \mathrm{~mL})$ for analyses of antioxidant properties.

\section{Antioxidant activity in linoleic acid system}

The antioxidant activity of phenolics against lipid peroxidation was measured by studying the peroxidation of linoleic acid using the ferric thiocyanate method (FTC), as described by Takao et al. [27] albeit with some modifications. During linoleic acid peroxidation, peroxides are formed and these compounds can oxidize $\mathrm{Fe}^{2+}$ to $\mathrm{Fe}^{3+}$. The $\mathrm{Fe}^{3+}$ ions form a complex with $\mathrm{SCN}^{-}$, which has a maximum absorbance at $500 \mathrm{~nm}$. Thus, a high absorbance value indicated a high peroxide formation during the emulsion incubation. A reaction mixture containing phenolic extract (100 $\mu \mathrm{g} / \mathrm{mL}, 0.2 \mathrm{~mL})$, linoleic acid emulsion ( $25 \mathrm{mg} / \mathrm{mL}$ in $99 \%$ ethanol, $0.2 \mathrm{~mL}$ ) and $50 \mathrm{mM}$ phosphate buffer ( $\mathrm{pH}=7.4,0.4 \mathrm{~mL}$ ) was incubated in the dark at $40{ }^{\circ} \mathrm{C}$. An aliquot $(0.1 \mathrm{~mL})$ of the reaction solution was then added to $70 \%(\mathrm{v} / \mathrm{v})$ ethanol (3 mL) and $30 \%(\mathrm{w} / \mathrm{v})$ ammonium thiocyanate $(0.1 \mathrm{~mL})$. Three min. after of the addition of 20 $\mathrm{mmol} / \mathrm{L}$ ferrous chloride in $3.5 \%(\mathrm{v} / \mathrm{v})$ hydrochloric acid $(0.1 \mathrm{~mL})$ to the reaction mixture, the absorbance of the resulting solution was measured at $500 \mathrm{~nm}$ using a Unic UV-2802 spectrophotometer. Aliquots were assayed every $24 \mathrm{~h}$. until the absorbance of the control solution (without phenolic extract) reached maximum value. Butylated hydroxytoluene (BHT) was used as a positive control. Three replicates were performed for the assessment of antioxidant activity of phenolics against lipid peroxidation in linoleic acid system.

\section{Scavenging activity of $\alpha, \alpha$-diphenyl- $\beta$-picrylhydrazy (DPPH) radicals}

The scavenging activity of phenolics against DPPH radicals was assessed according to the method of Larrauri et al. [28] with some modifications. Briefly, litchi phenolics at various concentrations (0.1 $\mathrm{mL}$ ) were mixed with $0.1 \mathrm{mM}$ DPPH-methanol $(2.9 \mathrm{~mL})$ solution. After the solution was incubated for $30 \mathrm{~min}$. at $25^{\circ} \mathrm{C}$ in dark, the decrease in absorbance was measured at $517 \mathrm{~nm}$. The control contained methanol instead of the phenolic extract solution while the blank contained methanol instead of DPPH solution. In the experiment, $L$-ascorbic acid and BHT were used as positive controls. The inhibition of $\mathrm{DPPH}^{\circ}$ radicals by these samples was calculated by the following equation: DPPH' radicals scavenging activity $/ \%=\left[1-\left(A_{\text {sample }}-A_{\text {blank }}\right) / A_{\text {control }}\right] \cdot 100$, which $A$ is the absorbance using sample, blank or control. Ascorbic acid and BHT were used as positive controls to compare their scavenging capacity with litchi phenolic compounds. Three replicates were carried out to determine scavenging activity of litchi phenolics against DPPH' radicals.

\section{Superoxide radical scavenging activity}

Determination of superoxide radical scavenging activity was conducted according to the method described by Siddhurajua et al. [29]. All solutions were prepared in $0.05 \mathrm{~mol} / \mathrm{L}$ phosphate buffer ( $\mathrm{pH}=7.8$ ). The photo-induced reactions were performed in an aluminium foil-lined box with two $30 \mathrm{~W}$ fluorescent lamps. The distance between the reaction solution and the lamp was adjusted until luminous 
intensity reached about 4,000 lux. An aliquot of various concentrations of litchi phenolics (30 $\mu \mathrm{L})$ was mixed with reaction buffer solution $(1.3 \mu \mathrm{mol} / \mathrm{L}$ riboflavin, $13 \mathrm{mmol} / \mathrm{L}$ methionine, $63 \mu \mathrm{mol} / \mathrm{L}$ nitro blue tetrazolium and $100 \mu \mathrm{mol} / \mathrm{L}$ EDTA, $\mathrm{pH}=7.8,3 \mathrm{~mL}$ ). The reaction solution was illuminated for $15 \mathrm{~min}$. at $25{ }^{\circ} \mathrm{C}$. The reaction mixture without any sample was used as a control. The superoxide radical scavenging activity was calculated by the relation $\left(1-A_{\text {sample }} / A_{\text {control }}\right) \cdot 100$, where $A$ is the absorbance using sample or control. Three replicates were performed.

\section{Reducing power}

The reducing power was determined according to the method of Oyaizu [30]. An aliquot (0.25 mL) of litchi phenolics at various concentrations was mixed with $200 \mathrm{mmol} / \mathrm{L}$ sodium phosphate buffer $(\mathrm{pH}=6.6,2.5 \mathrm{~mL})$ and $1 \%$ potassium ferricyanide $(2.5 \mathrm{~mL})$. The mixture was then incubated for $20 \mathrm{~min}$ at $50{ }^{\circ} \mathrm{C}$. After $10 \%$ trichloroacetic acid (w:v, $2.5 \mathrm{~mL}$ ) were added, the mixture was centrifuged at $650 \times$ $g$ for $10 \mathrm{~min}$. An aliquot (5 mL) of the upper layer was mixed with distilled water (5 mL) and $0.1 \%$ ferric chloride $(1 \mathrm{~mL})$ before the absorbance was measured at $700 \mathrm{~nm}$. The control contained methanol instead of litchi phenolic solution. A higher absorbance indicated a higher reducing power. Three replicates were conducted.

\section{Inhibitory effect on deoxyribose degradation}

The inhibitory effect of litchi phenolics on deoxyribose degradation was determined by measuring the reaction activity between either antioxidants and hydroxyl radicals (referred as non-site-specific scavenging assay) or antioxidants and iron ions (referred as site-specific scavenging assay), described by Lee et al. [23]. For the non-site-specific scavenging assay, an aliquot of litchi phenolics at different concentrations $(0.1-\mathrm{mL})$ was mixed with reaction buffer $\left(100 \mu \mathrm{mol} / \mathrm{L} \mathrm{FeCl}_{3}, 104 \mu \mathrm{mol} / \mathrm{L}\right.$ EDTA, 1.5 $\mathrm{mmol} / \mathrm{L} \mathrm{H}_{2} \mathrm{O}_{2}, 2.5 \mathrm{mmol} / \mathrm{L}$ deoxyribose, and $100 \mu \mathrm{mol} / \mathrm{L} \mathrm{L}$-ascorbic acid, $\mathrm{pH}=7.4,1 \mathrm{~mL}$ ) and then incubated for $1 \mathrm{~h}$. at $37^{\circ} \mathrm{C}$. An aliquot of $0.5 \%$ 2-thiobarbituric acid in $0.025 \mathrm{~mol} / \mathrm{L} \mathrm{NaOH}(1 \mathrm{~mL})$ and $2.8 \%$ trichloroacetic acid $(1 \mathrm{~mL})$ were added to the mixture, which was then heated for $30 \mathrm{~min}$. at $80{ }^{\circ} \mathrm{C}$. The mixture was cooled on ice and its absorbance was then measured at $532 \mathrm{~nm}$. Site-specific scavenging activity, which corresponded to the ability of litchi phenolics to chelate iron ions and interfere with hydroxyl radical generation, was measured using the same reaction buffer without EDTA. The control contained methanol instead of litchi phenolic solution. Percent inhibition of deoxyribose degradation was calculated as $\left(1-A_{\text {sample }} / A_{\text {control }}\right) \cdot 100$, where $A$ is the aborbance using sample or control. Three replicates were used for determination of the inhibitory effect on deoxyribose degradation.

\section{Total phenolic content}

Total phenolic content in the above-mentioned litchi extract was determined according to the method of Folin-Ciocalteu reaction [31], using gallic acid as standard. 


\section{Fruit treatment with litchi phenolic compounds}

Litchi phenolics were extracted from pericarp tissues, purified and then used for treatment of litchi fruit. The fruits were randomly distributed into six groups ( 90 fruits per group). For each treatment, three replicates were used. Fruits were immersed in $100 \mathrm{mg} / \mathrm{L}$ aqueous phenolic solution in a desiccator and then infiltrated under an air pressure of $53 \mathrm{kPa}$ for $3 \mathrm{~min}$. The fruit were air-dried for $1 \mathrm{~h}$. at $28{ }^{\circ} \mathrm{C}$, packed in polyethylene bag $\left(0.03 \mathrm{~mm}\right.$ thick) and then stored at $28^{\circ} \mathrm{C}$. The fruit treated with water was used as a control. The fruit from each replicate of each treatment after being held for 2, 4 or 6 days were sampled for measurements of pericarp browning index and electrolyte leakage.

\section{Pericarp browning assessment}

Pericarp appearance was assessed according to the method of Duan et al. [25] by measuring the extent of the total browned area on each pericarp of 30 fruits using the following scale: $1=$ no browning (excellent quality); 2 = slight browning; $3=<1 / 4$ fruit surface showing browning symptoms; $4=1 / 4-1 / 2$ surface showing browning symptoms and $5=>1 / 2$ surface showing browning symptoms (poor quality). The browning index was calculated as $\sum$ (browning scale $\times$ percentage of corresponding fruit within each class). The subjective evaluation of pericarp browning index correlated well with the objective determination of the value of the absorbance at $410 \mathrm{~nm}$ of the pericarp extract [32].

\section{Measurement of electrolyte leakage}

Electrolyte leakage was determined according to the method of Jiang and Chen [33]. Discs were removed with a cork borer ( $10 \mathrm{~mm}$ in diameter) from the equatorial region of 30 fruit. Thirty discs (about $2 \mathrm{~g}$ ) were rinsed twice, then incubated in $0.3 \mathrm{~mol} / \mathrm{L}$ mannitol in distilled water $(25 \mathrm{~mL})$ at $25{ }^{\circ} \mathrm{C}$, and finally shaken for $30 \mathrm{~min}$. Electrolyte leakage was determined with a conductivity meter (Model DDS-11A, Shanghai Scientific Instruments). The same batch of discs was boiled for 15 min. in 0.3 $\mathrm{mol} / \mathrm{L}$ mannitol in distilled water $(25 \mathrm{~mL})$ and then cooled to $25{ }^{\circ} \mathrm{C}$ to assess total electrolytes. The relative leakage was expressed as a percentage of the total electrolytes.

\section{Statistical analysis}

All analyses were performed in triplicate. The data were expressed as means \pm standard errors (SE) in six figures and then analyzed by SPSS (Version 10.0). One-way analysis of variance (ANOVA) and Tukey multiple comparisons were carried out to test any significant difference between the means. Differences between means at the $5 \%$ level were considered to be significant.

\section{Acknowledgements}

This work was supported partly by the International Foundation for Science (Grant No. E2265/3F), the National Science Foundation of China (Grant No. 0500353), and Guangdong Provincial Science Foundation of China (Grant No. 06200670 and 5300902). 


\section{References}

1. Bloknina, O.; Virolainen, E.; Fagerstedt, K.V. Antioxidants, oxidative damage and oxygen deprivation stress: a Review. Ann. Bot. 2003, 91, 179-194.

2. Halliwell, B.; Gutteridge, J.M.C. Free radicals in biology and medicine, 3rd ed.; Oxford University Press Inc.: New York, 1999.

3. Moskovitz, J.; Yim, K.A.; Choke, P.B. Free radicals and disease. Arch. Biochem. Biophys. 2002, 397, 354-359.

4. Simic, M.G. Mechanisms of inhibition of free-radical processed in mutagenesis and carcinogenesis. Mutat. Res. 1988, 202, 377-386.

5. Jiang, Y.; Duan, X.; Joyce, D.; Zhang, Z.; Li, J. Advances in understanding of enzymatic browning in harvested litchi fruit. Food Chem. 2004, 88, 443-446.

6. Bauer, A.K.; Dwyer-Nield, L.D.; Kell, K.; Koski, K.; Malkinson, A.M. Butylated hydroxytoluene (BHT) induction of pulmonary inflammation: A role in tumor promotion. Exp. Lung Res. 2001, 27, 197-216.

7. Gracia-Alonso, M.; De Pascual-Teresa, S.; Santos-Buelga, C.; Rivas-Gonzalo, J.C. Evaluation of antioxidant properties of fruits. Food Chem. 2004, 84, 13-18.

8. Soong, Y.Y.; Barlow, P.J. Antioxidant activity and phenolic content of selected fruit seeds. Food Chem. 2004, 88, 411-417.

9. Rice-Evans, C.; Miller, N.J.; Paganga, G. Antioxidant properties of phenolic compounds. Trends Plant Sci. 1997, 2, 152-159.

10. Jiang, Y.M.; Fu, J.R. Inhibition of polyphenol oxidase and the browning control of litchi fruit by glutathione and citric acid. Food Chem. 1998, 62, 49-52.

11. Gonzalez-Aguilar, G.A.; Ruiz-Cruz, S.; Soto-Valdez, H.; Vazquez-Ortiz, F.; Pacheco-Aguilar, R.; Wang, C.Y. Biochemical changes of fresh-cut pineapple slices treated with antibrowning agents. Int. J. Food Sci. Tech. 2005, 40, 377-383.

12. Zhang, D.L.; Quantick, P.C.; Grigor, J.M. Changes in phenolic compounds in litchi (Litchi chinensis Sonn.) fruit during posthravest storage. Postharv. Biol. Tech. 2000, 19, 165-172.

13. Sarni-Manchado, P.; Le Roux, E.; Le Guerneve, C.; Lozano, Y.; Cheynier, V. Phenolic composition of litchi fruit pericarp. J. Agr. Food Chem. 2000, 48, 5995-6002.

14. Zhao, M.; Yang, B.; Wang, J.; Li, B.; Jiang, Y. Identification of the major flavonoids from pericarp tissues of lychee fruit in relation to their antioxidant activities. Food Chem. 2006, 98, 539-544.

15. Chang, L.W.; Yen, W.J.; Huang, S.C.; Duh, P.D. Antioxidant activity of sesame coat. Food Chem. 2002, 78, 347-354.

16. Luximon-Ramma, A.; Bahorun, T.; Soobrattee, M.A.; Aruoma, O.I. Antioxidant activities of phenolic, proanthocyanidin, and flavonoid compontents in extracts of Cassia fistula. J. Agr. Food Chem. 2002, 50, 5042-5047.

17. Deithton, N.; Brnnan, R.; Finn, C.; Davies, H.V. Antioxidant properties of domesticated and wild Rubus species. J. Agr. Food Chem. 2000, 80, 1307-1313.

18. Gil, M.I.; Tomas-Barberan, F.A.; Hess-Pierce, B.; Holcroft, D.M.; Kader, A.A. Antioxidant activity of pomegranate juice and its relationship with phenolic composition and processing. J. Agr. Food Chem. 2000, 48, 4581-4589. 
19. Burns, J.; Gardner, P.T.; Mcphail, D.B.; O’nell, J.; Crawford, S.; Morecroft, I.; Lister, C.; Matthews, D.; Maclean, M.R.; Lean, M.E.J.; Duthie, G.G.; Crozier, A. Antioxidant activity, vasodilation capacity and phenolic content of red wines. J. Agr. Food Chem. 2000, 48, 220-230.

20. Sanchez-Moreno, C. Methods used to evaluate the free radical scavenging activity in foods and biological systems. Food Sci. Technol. Int. 2002, 8, 121-137.

21. Sun, J.; Chu, Y.F.; Wu, X.; Liu, R.H. Antioxidant and antiproliferative activities of common fruits. J. Agr. Food Chem. 2002, 50, 7449-7454.

22. Rollet-Labelle, E.; Grange, M.J.; Elbim, C.; Marquetty, C.; Gougerot-Pocidalo, M.A.; Pasquier, C. Hydroxyl radical as a potential intracellular mediator of polymorphonuclear neutrophil apoptosis. Free Radical Bio. Med. 1998, 24, 563-572.

23. Lee, J.C.; Kim, H.R.; Kim, J.; Jang, Y.S. Antioxidant property of an ethanol extract of the stem of Opuntia ficus-indica var. Saboten. J. Agr. Food Chem. 2002, 50, 6490-6496.

24. Zhou, Y.; Lu, Y.; Wei, D. Antioxidant activity of a flavnoid-rich extract of Hypericum perforatum L. in vitro. J. Agr. Food Chem. 2004, 52, 5032-5039.

25. Duan, X.W.; Jiang, Y.M.; Su, X.G.; Liu, H.; Li, Y.B.; Zhang, Z.Q.; Zheng, Y.H.; Jiang, W.B. Role of pure oxygen treatment in browning of litchi fruit after harvest. Plant Sci. 2004, 167, 665-668.

26. Liu, X.S.; Jiang, Y.M.; Chen, F.; Zhang, D.L.; Li, Y.B. The relationship between the browning in pericarp of litchi (Litchi Chinensis Sonn.) fruit and polyphenol oxidase, peroxidase, phenolics and their compartmentation. Acta Bot. Austro Sin. 1991, 7, 95-98 (in Chinese).

27. Takao, T.; Kitatani, F.; Watanabe, N.; Yagi, A.; Sakata, K. A simple screening method for antioxidants and isolation of several antioxidants produced by marine bacteria from fish and shellfish. Biosci. Biotech. Bioch. 1994, 58, 1780-1783.

28. Larrauri, J.A.; Sanchez-Moreno, C.; Saura-Calixto, F. Effect of temperature on the free radical scavenging capacity of extracts from red and white grape pomace peels. J. Agr. Food Chem. 1998, 46, 2694-2697.

29. Siddhurajua, P.; Mohanb, P.S.; Bechera, K. Studies on the antioxidant activity of Indian Laburnum (Cassia fistula L.): a preliminary assessment of crude extracts from stem bark, leaves, flowers and fruit pulp. Food Chem. 2002, 79, 61-67.

30. Oyaizu, M. Studies on products of browning reaction: antioxidative activity of products of browning reaction prepared from glucosamine. J. Nutr. 1986, 44, 307-315.

31. Singleton, V.L.; Rossi, J.A. Colorimetry of total phenolics with phosphomolybdic-phosphotungstic acid reagents. Am. J. Enol. Viticult. 1965, 16, 144-158.

32. Jiang, Y.M. Role of phenolics, polyphenol oxidase and phenols in lychee pericarp browning. J. Sci. Food Agr. 2000, 80, 305-310.

33. Jiang, Y.M.; Chen, F. A study on polyamine change and browning of fruit during cold storage of litchi. Postharv. Biol. Tech. 1995, 5, 245-250.

Sample Availability: Available from the authors.

(c) 2007 by MDPI (http://www.mdpi.org). Reproduction is permitted for noncommercial purposes. 